using the facilities of electronic computing establishments elsewhere-particularly at the University of Manchester, the generosity of which in this respect has been greatly appreciated by several other northern universities as well as Liverpool. More than four years ago, however, it was already clear that the University of Liverpool should be equipped with its own computer, and detailed plans were made for the expansion of the Laboratory. It was therefore with very keen disappointment that the University learned two years ago that money could not be provided at that time by the University Grants Committee for the provision of a computer.

A survey made in the University had established the faet that the lack of an adequate computing service was causing research in some departments to be retarded seriously - particularly in the fields of nuclear physics and oceanography. In view of this situation, the University Council decided that a computer must somehow be provided and an appeal was launched among local business concerns and friends of the University for donations towards the cost of purchasing a machine. The response was generous particularly as the appeal was made within a year of the major appeal to finance the general building development of the University-and as a result the University was able to place an order with the English Electric Co., Ltd., for a Deuce, the remaining balance of the cost being advanced by the University itself. At the same time the staff of the Laboratory was increased and its name changed to the Computer Laboratory, Mr. Andrew Young being appointed as its first director.

The machine was installed and came into operation last July. It is a 64-column Deuce, which is at present equipped with punched card input and output mech. anisms. A comprehensive range of punched card ancillary equipment--card punches, sorter, reproducer and tabulator- has also been installed; a cardoperated typewriter is due for early delivery. In addition, paper tape input and output devices and the necessary tape editing ancillary equipment have been ordered, but have not yet been delivered.
The Computer Laboratory was officially inaugurated at an open day held on October 28, when the University entertained donors to the appeal fund and members of Council and Senate. The guests were welcomed by the Vice-Chancellor, Sir James Mountford, and were shown over the Laboratory by the staff; the Director gave an account of the work being done in the Laboratory.

It is already clear that the computer is meeting a very real need. Extensive use of the machine is being made, as expected, by the Departments of Applied Mathematics, Physics-mainly analysing results of experiments made on the University's large synchrocyclotron-and Oceanography as well as several departments in the Faculty of Engineering, including the new Department of Building Science.

What has surprised - and gratified-the University, however, is the unexpectedly large use of the machine by departments which had not hitherto been expected to use it extensively, if at all. Sorne of the most frequent users are members of a group of physiologists working on a problem of liver function. Members of the Department of Psychology and of the Medical Research Council are now analysing the results of gerontological studies with the computer, which, because of its ability to cope with the heavy arithmetic involved in factor analysis, has enabled them to extend their work. In addition, educational, economic and social scientific surveys have been helped by the new computing facilities available.

Training in programming and using the computer and its ancillary equipment is given regularly to members of the staff of the University, research students, and to outside users, a number of whom are making use of the machine on a basis of time-hire.

It is now a commonplace occurrence that the installation of a computer leads to an expansion in the scope of the work undertaken in an institution, and it is already abundantly clear that in this respect the installation in Liverpool will prove to be no exception. The University is proud of its new project, and is confident that the decision to embark on it will be fully justified.

\title{
BRITISH ELECTRICAL AND ALLIED INDUSTRIES RESEARCH ASSOCIATION
}

\begin{abstract}
A NEW format has been adopted for the 1958 annual report of the Electrical Research Association (Thirty-eighth Annual Report for the year ended 31st December 1958. Pp. 103. Leatherhead: Electrical Research Association, 1959). The report, which is attractively reproduced, departs from previous practice in having some fifteen illustrations, mostly photographs relating to researeh projects. One diagrammatic illustration of special interest shows the proportions of the income of the Association coming from various sources and the distribution of expenditure among the main fields of research, in administration and in services to members.

The total income of the Association for the year was just over $£ 458,000$, subscriptions from members totalling some $£ 213,000$, income from directly sponsored researches earning nearly $£ 113,000$, and the grant from the Department of Scientific and
\end{abstract}

Industrial Research contributing $£ 100,000$. From the chart showing the distribution of expenditure it appears that some 9 per cent is used in administration. A slightly greater amount represents services to members which, in addition to general technical liaison, cover the answering of requests for advice and information and the provision of abstracts. Research expenditure appears under seven headings, divided as percentages of the total exponditure, roughly, as follows :

$\begin{array}{cccc}\text { Properties of materials } & 19 & \text { Applications of electricity } & 12 \\ \text { System problems } & 14 & \text { Transmission } & 6 \\ \text { Control and transformation } & 10 & \text { Specialized plant } & 10 \\ \text { Miscellaneous researches } 9 & \end{array}$

On the basis of expenditure, properties of materials thus represents, by a substantial margin, the biggest research effort of the Association, and it is evident from the report that this effort, which is devoted largely to insulation, has contributed both to funda- 
mental knowledge and to technological progress. Much of the Association's technological work in this field has contributed to the drafting of British Standard specifications and similarly, at the international level, to the recommendations of such bodies as the International Electrotechnical Commission. During the past year the Electrical Research Association's recommendations relating to electrode systems for electric strength tests and for methods of measurement of permittivity and loss angle have been so adopted.

Work conducted at the National Physical Laboratory on the effects of electron and neutron irradiation of polythene is reported. It has been shown that the loss tangent of the material is little affected by irradiation dosages up to $10 \mathrm{Mrads}$, but thereafter increases due to oxidation.

Among the investigations of a fundamental character concerning the phenomena of instability in dielectrics, one may be mentioned dealing with the formation of gas in impregnated insulation. This has established the relation between moisture content and the stress required to initiate gas production. It has been possible to observe the slow growth of breakdown channels in a very viscous liquid and this forms the subject of one of the illustrations in the report.

A reliable technique has been developed for measuring the electric strength of liquefied gases, it having been established that the state of the electrode surfaces and particularly the degree of oxidation have a marked influence on the result. The parts played by anode and cathode have been separated by using electrodes in which the cathode and anode surface were different.

The influence of impurities on the magnetic properties of silicon-iron transformer sheet has been under investigation at the laboratories of the British Iron and Steel Research Association. It has been shown that, with respect to hysteresis loss, nitrogen is much more harmful than carbon, and two methods of minimizing the ill-effects of nitrogen are being examined. One method involves applying a thin coating of aluminium to laminations before annealing while the other utilizes a small admixture of titanium.

Theoretical work on deviations from Ohm's law in semiconductors has predicted that in sufficiently strong fields mobility should decrease with the $0 \cdot 8$ th power of the field strength. This prediction has been confirmed by measurements made at Purdue University.
Circuit breaking and associated fundamental studies in arc physies continue to constitute an important part of the research programme. The temperature within the conducting core of the arc and, in particular, the formation of successive discrete cores as the current increases, have been studied in terms of dissociation and ionization, and it has been shown that the pinch pressures occurring at the electrodes outweigh the effects of natural convection and may provide an explanation of the phenomena of metal transfer in welding arcs.

Work on the creep properties of steel continues and is being extended. The first test-results have been obtained on the bursting of thick-walled pipes under creep conditions. A new laboratory to meet the needs of the augmented programme of work on creep testing is to be built at Leatherhead.

A result of considerable industrial significance has been obtained in the course of the programme of work on flame proofness and intrinsic safety. A reevaluation of the maximum safe-gap for hydrogen made with improved research technique has shown the safe gap to be appreciably greater than was previously accepted. The value has been established as 11 mils. This opens up the possibility of designing flame-proof apparatus for use in hydrogen and some of the other most explosive gases.

The rural electrification work of the Association, which is concerned very largely with the application of electricity to agriculture and to horticulture, has, in the past, embodied a considerable programme of research on plant environment. This continues but it is now supplemented by a parallel programme on animal environment.

In a foreword to the report the president, Sir Josiah Eccles, points out that we are entering an era in which the scale and complexity of equipment and of automatic control systems will be such as to render capital charges a dominant factor in industrial costs.

There will thus be an increasing premium on ingenuity and skill in producing more effective and cheaper equipment which, in effect, means an increasing emphasis on research. Bearing in mind that the vast majority of manufacturing firms in Great. Britain employ less than 500 people and that many problems can be better tackled co-operatively than in specialized laboratories, it is evident that research associations have an important part to play in the effort to develop to the full the nation's scientific potential. In furthering this development the greatest responsibility falls, almost certainly, to the electrical industry.
J. Greig

\section{FLOW PROPERTIES OF BIOLOGICAL SYSTEMS}

\begin{abstract}
A
MEETING, under the joint auspices of the Faraday Society (Colloid and Biophysics Committee) and the British Society of Rheology, was held during September 23 and 24 in the School of Physiology of the University of Oxford. On the first day, the flow properties of various biological systems were discussed, while the second day was devoted entirely to blood and blood vessels. The attendance of more than seventy included a number of overseas guests.

The Conference was opened by Prof. P. R. Allison. Nuffield professor of surgery, who welcomed the
\end{abstract}

meeting to Oxford and spoke of the increasing importance of rheology in medicine and surgery. A general introductory lecture, under the chairmanship of Prof. M. Reiner (Haifa, Israel), was given by Dr. A. S. Lodge. Many of his audience were not rheologists and, for their benefit, Dr. Lodge outlined the scope and methodology of this branch of physics.

Several papers were read which concerned uterine cervical mucus and the connective tissue of the cervix. Dr. F. K. Beller (Tübingen, W. Germany) described 